Supplement of Biogeosciences Discuss., 11, 16447-16495, 2014

http://www.biogeosciences-discuss.net/11/16447/2014/

doi:10.5194/bgd-11-16447-2014-supplement

(C) Author(s) 2014. CC Attribution 3.0 License.

(c) (i)

Supplement of

\title{
Recycling and fluxes of carbon gases in a stratified boreal lake following experimental carbon addition
}

H. Nykänen et al.

Correspondence to: H. Nykänen (hannu.k.nykanen@jyu.fi) 


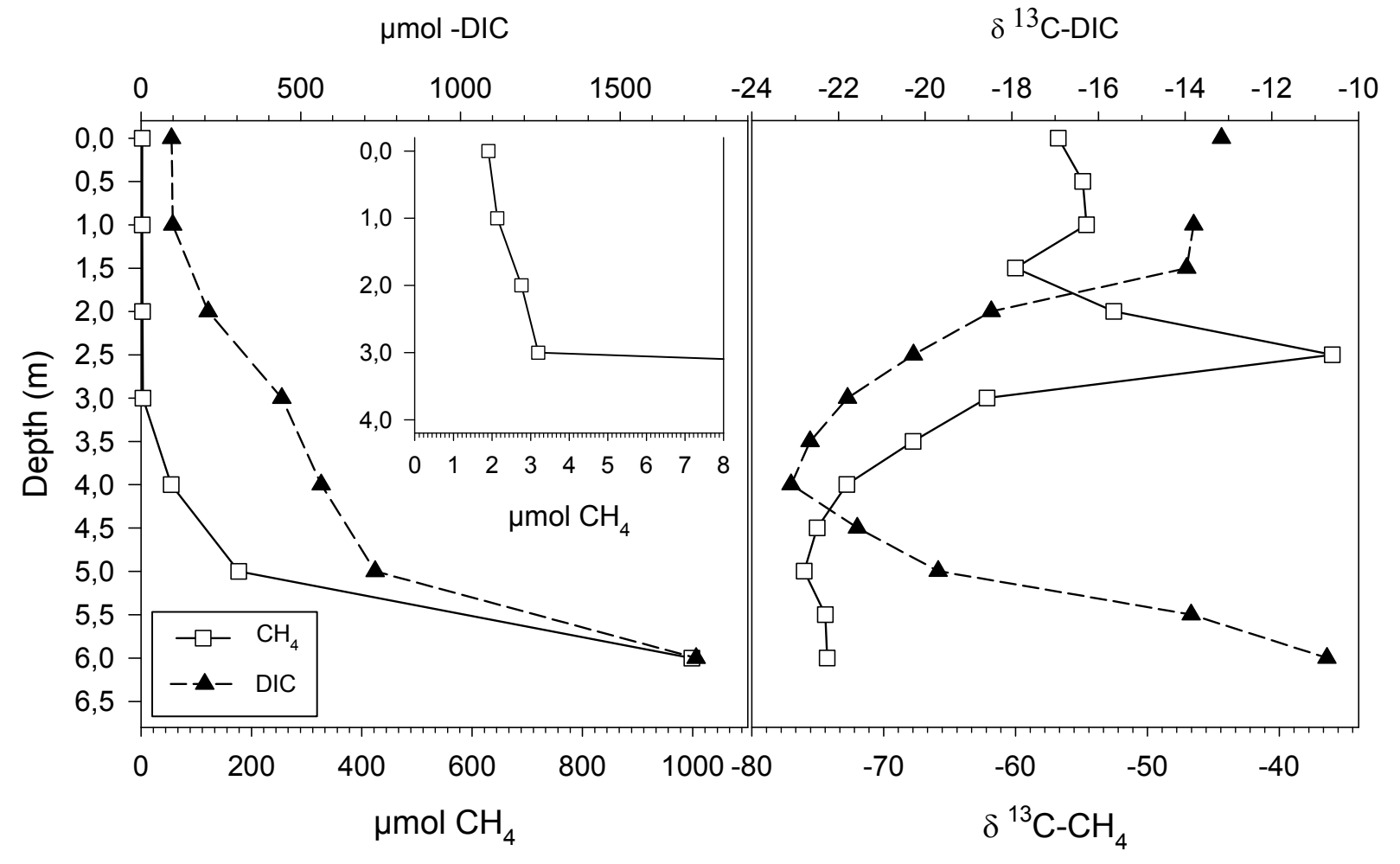

Supplementary Fig.1. Water column concentrations and $\delta 13 \mathrm{C}-\mathrm{CH} 4$ for $\mathrm{CH} 4$ (open box) and DIC concentrations and $\delta 13 \mathrm{C}$ (filled triangles) on 27.8.2008, when sampling was with $0.5 \mathrm{~m}$ spacing. Superimposed insert shows $\mathrm{CH} 4$ concentration in the upper water column. 